AperTO - Archivio Istituzionale Open Access dell'Università di Torino

\title{
Grafting of gallic acid to metallic surfaces
}

\section{This is the author's manuscript}

Original Citation:

Availability:

This version is available http://hdl.handle.net/2318/1731111

since 2020-02-26T10:17:44Z

Published version:

DOI:10.1016/j.apsusc.2020.145615

Terms of use:

Open Access

Anyone can freely access the full text of works made available as "Open Access". Works made available under a Creative Commons license can be used according to the terms and conditions of said license. Use of all other works requires consent of the right holder (author or publisher) if not exempted from copyright protection by the applicable law. 


\title{
Grafting of gallic acid to metallic surfaces
}

Sara Ferraris ${ }^{1}$, Martina Cazzola ${ }^{1}$, Graziano Ubertalli ${ }^{1}$, Enrico Prenesti ${ }^{3}$, Silvia Spriano ${ }^{1}$

${ }^{1}$ Politecnico di Torino, Department of Applied Science and Technology, Institute of Materials Physics and Engineering, C.so Duca degli Abruzzi 24, Torino, 10129, Italy.

${ }^{2}$ Università del Piemonte Orientale UPO, Department of Health Sciences, Via Solaroli 17, Novara, 28100, Italy

${ }^{3}$ Università degli Studi di Torino, Department of Chemistry, Via Pietro Giuria 7, Torino, 10125, Italy.

\begin{abstract}
The protection against bacteria, oxidation and corrosion is crucial for metals. Natural molecules can offer numerous of these properties, however they are poorly explored for the surface modification of metals. Gallic Acid (GA) was selected as model molecule for polyphenols to investigate the mechanisms involved in its grafting to the metallic surfaces. Ti6AI4V, AISI-204-Cu and AISI-304 stainless steels were used as substrates. GA solutions were prepared in different media (ultrapure water, TRIS/HCl buffer, TRIS/HCl buffer containing $\mathrm{Ca}^{2+}$ ions) to explore the role of the ionic composition and $\mathrm{pH}$ in the GA bonding ability to metallic substrates. Solutions were analyzed by means of UV and FTIR spectroscopies. The samples were characterized by means of FTIR spectroscopy and the Folin\&Ciocalteu tests to evaluate GA presence and activity. Surface wettability was also evaluated.
\end{abstract}

GA was effectively grafted to all the surfaces maintaining its redox activity. FTIR and wettability tests confirmed its presence on the modified surfaces.

A crucial role of $\mathrm{pH}$ and $\mathrm{Ca}^{2+}$ presence in solutions was demonstrated and correlated to the formation of coordination compounds in solution and at the metal surface. It was observed that the surface chemical composition and the presence of functional groups affect the molecular grafting ability. 


\section{Graphical abstract}

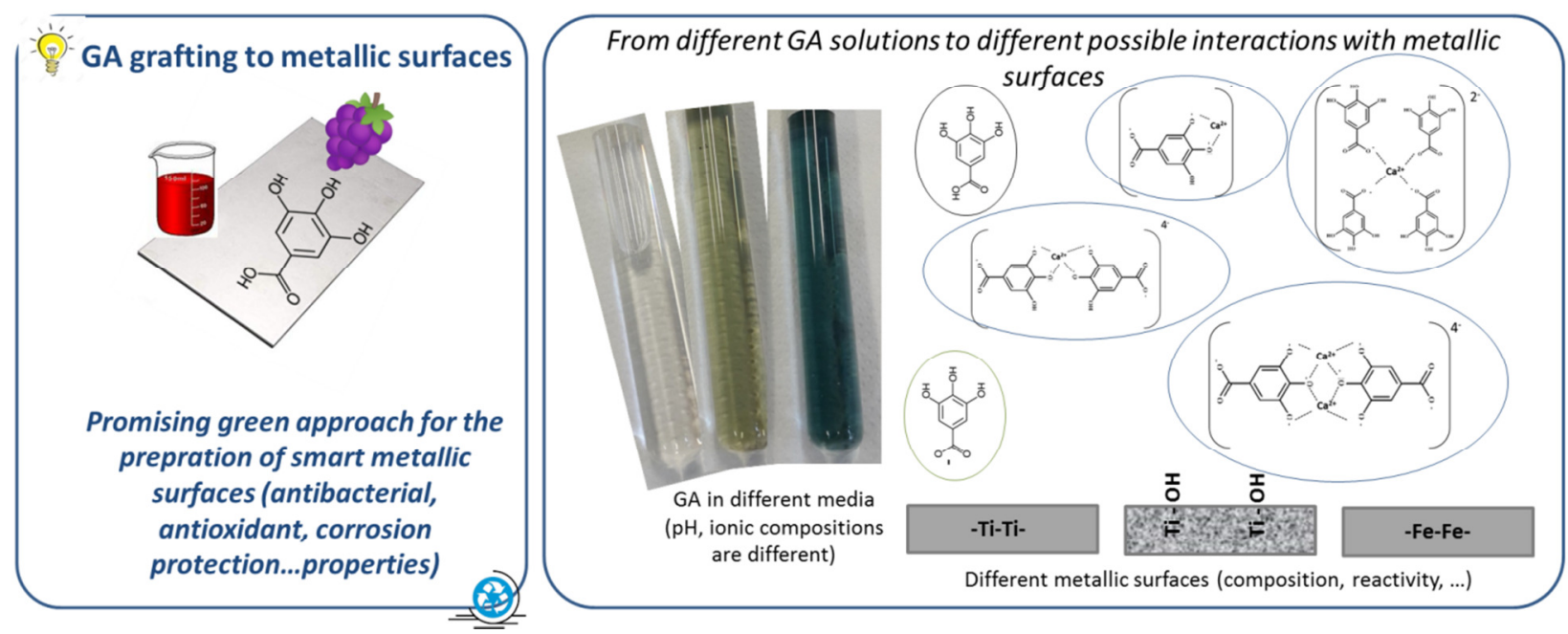

Keywords: metallic surfaces; gallic acid; surface functionalization; polyphenols; titanium; steel 


\section{Introduction}

Natural polyphenols are gaining increasing interest in many applications because of their peculiar properties, such as the action against oxidation, inflammation, cancer and bacteria [1-3]. Moreover, they can be obtained as high added value molecules from some industrial byproducts (e.g. food and wine production) supporting a sustainable use of the resources.

Gallic Acid (3,4,5-trihydroxybenzoic acid, henceforth GA) is a simple molecule, belonging to the polyphenol family, present in many plants (e.g. grapes and tea) as well as in foods and beverages [4, 5]. It is often used as a standard reference for the quantification of the polyphenols (e.g. in the Folin \& Ciocalteu test) [6] and it possesses numerous properties of interest for several applications (e.g. antioxidant, antibacterial and anticancer) [7-9]. It can be considered a good model molecule for polyphenols as well as an interesting compound for its intrinsic properties.

Numerous studies on its behavior as a pure molecule, in addition to some attempts of its coupling with materials for biomedical applications have been reported in the literature. For example, GA was coupled with chitosan in order to improve its antioxidant ability [7] and with gold nanoparticles to enhance the antibacterial activity [8]. Moreover, the authors successfully grafted GA to various bioactive glasses [10, 11, 12] and to bioactive titanium [13] for bone contact applications.

The interest for GA and polyphenols is not limited to the biomedical field; in fact antioxidant and antibacterial activities have been investigated in the food preservation context [14], their ability to bind proteins for the development of innovative surfaces for sensing and catalyst applications has been explored [15] and a possible corrosion protection effect on steel surfaces has been cited [16, 17].

In this context, the possibility to graft GA and polyphenols on metallic surfaces appears an interesting opportunity to confer the peculiar properties of polyphenols (e.g. antioxidant, antibacterial and corrosion protection) to the metal surface. GA and polyphenols can substitute some potentially toxic compounds (such as the disinfectants and cleaning products $[18,19]$ ) with the natural ones. This environmental friendly approach is extremely promising for the industrial standpoint.

The aim of the present research work is the investigation of the ability and mechanism of grafting of GA on some metallic surfaces. The Ti6AI4V alloy, polished and chemically treated to obtain a nanotextured oxide layer rich in $\mathrm{OH}$ groups, as well as 304 and 204-Cu stainless steels have been considered as substrates in order to explore metals of interest in different applications, as well as surfaces with different surface chemical composition and functional groups. The solutions of GA have been prepared for the functionalization process in different media (ultrapure water, TRIS/HCl buffer and TRIS/HCl buffer added with $\mathrm{CaCl}_{2}$ ) in order to investigate the role of $\mathrm{pH}$ and the ionic composition on $\mathrm{GA}$ grafting ability to metallic surfaces. In fact, in a previous work [13] the authors found a crucial role of pH (7.4) and the Ca presence in GA binding to the titanium surfaces.

The GA solutions were analyzed by means of UV and FTIR spectroscopies in order to investigate the chemical state of the GA molecule in the different media. Different techniques have been used in order to verify the presence and reactivity (redox activity) of the grafted GA on the functionalized metallic surfaces: FTIR spectroscopy, Folin \& Ciocalteu test (adapted to the solid surfaces), and contact angle measurements. 


\section{Materials and methods}

\section{Samples preparation}

The Ti6Al4V samples (discs with $10 \mathrm{~mm}$ diameter and $2 \mathrm{~mm}$ thickness) were obtained from cylindrical bars (ASTM B348, Gr5, Titanium Consulting and Trading) and Stainless steels 304 and $204 \mathrm{Cu}$ samples (square samples $1 \times 1 \mathrm{~cm}$ area, $2 \mathrm{~mm}$ thickness) were obtained from plates (Outokumpu Spa) by means of automatic cutting (ATA Brillant 220, with abrasive alumina wheel). All specimens were polished with SiC abrasive papers up to 4000 grit. Samples will be named Ti6Al4V - MP, SS 304 and SS 204-Cu.

After polishing, the samples were washed once for $5 \mathrm{~min}$ in acetone and twice for $10 \mathrm{~min}$ in ultrapure water with an ultrasonic bath and let it dry in air.

A part of the Ti6Al4V samples underwent a patented chemical treatment (hydrofluoric etching followed by hydrogen peroxide oxidation) $[19,20]$ in order to develop a surface nanotextured oxide layer rich in hydroxyl groups, potentially useful for biomolecular grafting $[13,21]$. The chemically treated Ti6Al4V samples will be named Ti6AI4V - CT from now on.

Preparation of the solutions of Gallic Acid

Gallic Acid 8GA , 3,4,5-Trihydroxybenzoic acid, 97.5-102.5\% titration, G7384, Sigma-Aldrich, St. Louis, MO, USA) was dissolved in different media (ultrapure water, TRIS/HCl buffer and calcium chloride solution 292 $\mathrm{mg} / \mathrm{l}$ in TRIS/HCl buffer solution) at $1 \mathrm{mg} / \mathrm{ml}$ concentration. Solutions will be named: GA (water), GA $(T R I S / H C l)$ and $\mathrm{GA}\left(\mathrm{TRIS} / \mathrm{HCl}+\mathrm{CaCl}_{2}\right)$. The media were selected in order to investigate the effect of $\mathrm{pH}$ and the ionic composition in the GA grafting ability to metallic surfaces. The $\mathrm{Ca}^{2+}$ ions were selected as allowable mediators for GA binding to metallic surfaces on the basis of a previous research of the authors [13].

The solutions were characterized by means of macroscopic observation of their appearance, $\mathrm{pH}$ measurements (Edge pH, HANNA Instruments), UV spectroscopy (UV-2600 Shimadzu) and Fourier Transformed Infrared Spectroscopy (FTIR, Thermo Scientific ${ }^{\mathrm{TM}}$ Nicolet $^{\mathrm{TM}}$ iS50 FTIR Spectrometer).

\section{Surface functionalization}

Titanium samples underwent an UV-C irradiation (1h) before functionalization in order to activate the surface for grafting [13].

For all the substrates, each sample was soaked in the GA solution for $3 \mathrm{~h}$ at $37^{\circ} \mathrm{C}$ in the dark. At the end of the soaking period, the samples were gently washed twice in ultrapure water and let it dry in air in the dark.

\section{Detection of GA on functionalized surfaces}

The presence of the grafted GA on the functionalized surfaces was investigated by means of Fourier Transformed Infrared Spectroscopy (FTIR, Thermo Scientific ${ }^{\mathrm{TM}}$ Nicolet $^{\mathrm{TM}}$ iS50 FTIR Spectrometer) in ATR mode. This technique gives information on the functional groups exposed on the surfaces after GA grafting and is of interest in the investigation of the molecule orientation and grafting mechanisms.

The presence and activity of the grafted GA was measured on the metallic samples by means of the Folin\&Ciocalteu method. This technique is widely used for the quantification of total phenols in a liquid 
phenolic mixture by using GA as a standard and adapted by the authors to the analysis of the solid samples as described in previous works $[11,23]$. In brief, each functionalized sample was soaked in $8 \mathrm{ml}$ of ultrapure water and $0.5 \mathrm{ml}$ of the Folin\&Ciocalteu phenol reagent ( $2 \mathrm{M}$ with respect to acid, Sigma Aldrich) and $1.5 \mathrm{ml}$ of $\mathrm{Na}_{2} \mathrm{CO}_{3}(20 \% \mathrm{w} / \mathrm{V})$ were sequentially added. After $2 \mathrm{~h}$, the samples were extracted and the absorbance of the solutions at $760 \mathrm{~nm}$ recorded with an UV spectrophotometer (UV-2600 Shimadzu). GA was quantified in accordance with a standard calibration curve $[11,23]$. Since the test is based on a redox reaction, the results give information both on the amount and on the redox activity of the grafted molecule.

Surface wettability was evaluated through the measurement of the static contact angle by the sessile drop method (Kruss DSA 100), using ultrapure water as a wetting fluid. A drop ( $5 \mu \mathrm{l}$ ) of ultrapure water was deposited on the sample surface with a micro-pipette and the contact angle measured through the instrument software.

\section{Results and discussion}

The UV spectra, the appearance of the GA solutions in different media and the hypothesized chemical structures of the molecule are reported in Figure 1.

The solution of GA in water has an acidic $\mathrm{pH}=3$ and a colorless appearance (Figure 1a). The UV spectrum of the solution (Figure 1d) evidences a peak at $269 \mathrm{~nm}$, typical of GA in acidic media [24] and consistent with its fully protonated form (Figure 1a).

The solution of $\mathrm{GA}$ in TRIS/HCl has a neutral $\mathrm{pH}=7.4$ (the physiological value) and the color of the solution turns to green (Figure $1 \mathrm{~b}$ ) due to the deprotonation of the carboxylic group [25] and to the possible presence of oxidized molecules (quinone form). The UV spectrum of the solution (Figure 1d) evidences the most intense peak at $259 \mathrm{~nm}$ and the appearance of two shoulders at about $338 \mathrm{~nm}$ and $443 \mathrm{~nm}$ which can be associated with the deprotonation of the carboxylic group, with the polymerization of GA molecules in solution [26] and with the presence of oxidized molecules (quinone) [17].

$\mathrm{GA}$ in TRIS/HCl solution containing $\mathrm{Ca}^{2+}$ ions has the same $\mathrm{pH}$ of the TRIS/HCl one $(7.4$, the physiological $\mathrm{pH}$ ), but the color turns to blue (Figure 1c) due to the formation of a GA-metal ion complex [17]. The UV spectrum of the solution (Figure 1d) evidences the most intense peak at $259 \mathrm{~nm}$, which presents a moderate shoulder if compared to the one of GA in water, and the appearance of a broad peak at about $640 \mathrm{~nm}$, which can be associated with the formation of a GA-metal ion complex [24, 27]. Different gallic acid calcium complexes can be hypothesized (Figure 1c). The molecular structures are reported in the planar form for simplicity, but the stereochemistry of the GA complexes has not been investigated and is out of the scope of this work. Even if at $\mathrm{pH} 7.4$ only the carboxylic group of GA is deprotonated (deprotonation of $\mathrm{OH}$ phenolic groups occurs at $\mathrm{pH}$ higher than 8.5) [25], the formation of a calcium gallate complex by means of the interaction between $\mathrm{Ca}^{2+}$ ions and gallic acid phenolic $\mathrm{OH}$ becomes possible due to the high stability of the formed complex. Moreover it should be underlined that the bonding of the $\mathrm{Ca}^{2+}$ ion to the phenolate moiety of the ligand molecule (gallate) protects gallic acid from oxidation. The significant reduction of the shoulders at about $338 \mathrm{~nm}$ and $443 \mathrm{~nm}$ in the GA (TRIS/ $\mathrm{HCl}+\mathrm{CaCl}_{2}$ ) UV spectrum (Figure 1d) supports this hypothesis. 


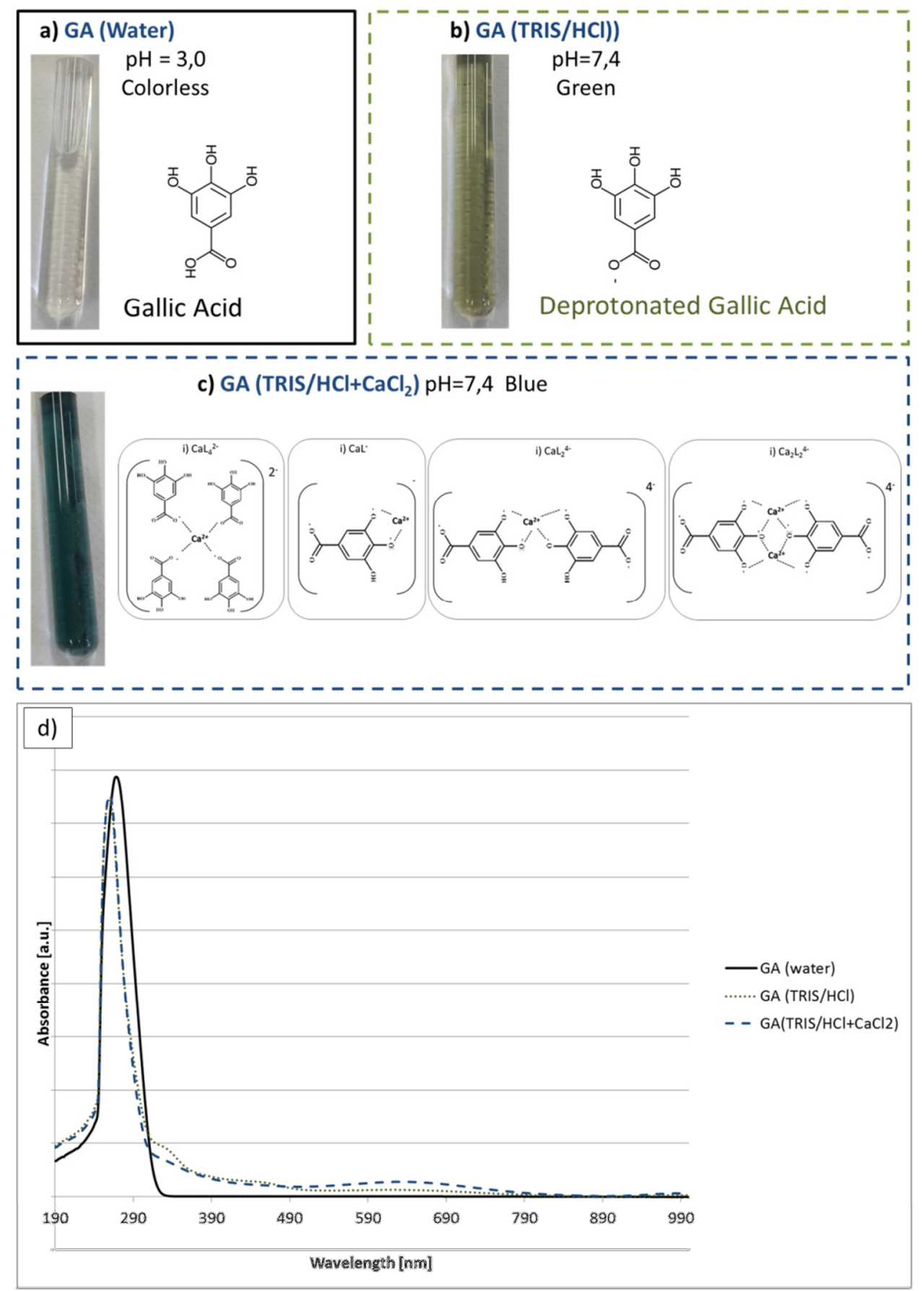

Figure 1: Appearance, $\mathrm{pH}$ and the hypothesized chemical state of the molecule of $\mathrm{GA}$ in solution in water (a), TRIS/ $\mathrm{HCl}$ (b) and TRIS/ $\mathrm{HCl}+\mathrm{CaCl}_{2}$ (c) and UV spectra of the same solutions (d).

FTIR spectra of the GA powder and $\mathrm{GA}$ solutions in water, $\mathrm{TRIS} / \mathrm{HCl}$ and $\mathrm{TRIS} / \mathrm{HCl}+\mathrm{CaCl}_{2}$ media are reported in Figure 2. 


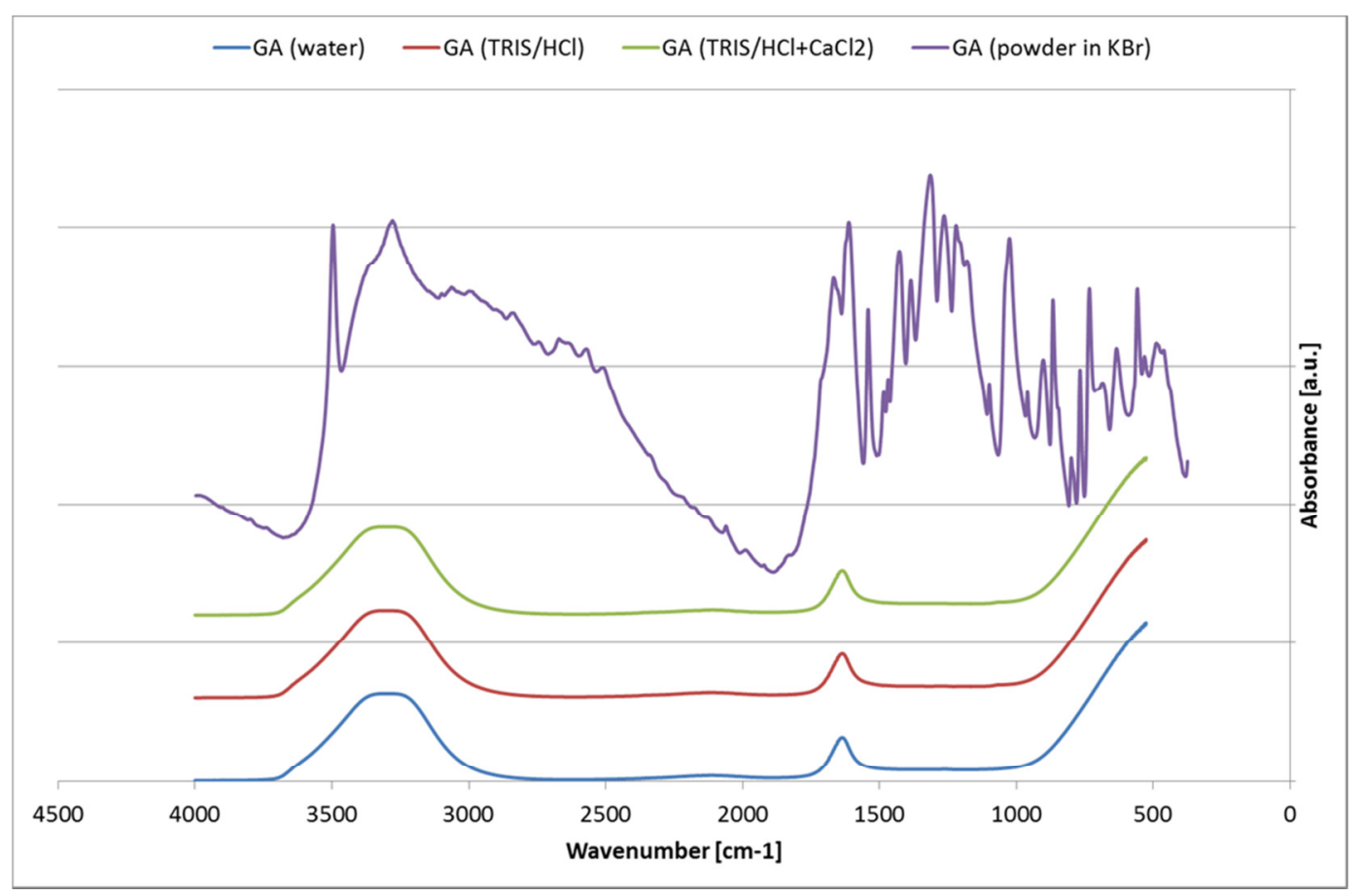

Figure 2: $\mathrm{FTIR}$ spectra -of $\mathrm{GA}$ powder and $\mathrm{GA}$ solutions in water, $\mathrm{TRIS} / \mathrm{HCl}$ and $\mathrm{TRIS} / \mathrm{HCl}+\mathrm{CaCl}_{2}$ media.

The spectrum of the GA powder is consistent with the results reported in the literature $[28,29,30]$ with the main peaks at about 3500 and $3200 \mathrm{~cm}^{-1}$, attributable to the $\mathrm{OH}$ stretching of the phenolic groups, and a characteristic fingerprint between 1800 and $550 \mathrm{~cm}^{-1}$, which evidences signals at about $1700 \mathrm{~cm}^{-1}$ and 1029 $\mathrm{cm}^{-1}$, associated with the carbonyl group and the benzene ring respectively [30].

The spectra of the GA solutions in the different media are almost equal (no differences attributable to the medium can be evidenced by this technique), but are significantly different from the one of the GA powder. In particular, the disappearance of the fingerprint can be observed, together with a broadening of the signal in the $3200-3500 \mathrm{~cm}^{-1}$ region. These modifications can be attributed to a partial polymerization of the GA molecules in the solution $[26,31]$.

In conclusion, we can assess that GA is present in all the solutions as partially polymerized (FTIR), but with deprotonated carboxylic groups and a higher degree of polymerization in the solutions at $\mathrm{pH}=7.4$ (UV, color of the solutions). Moreover, GA forms metal-ion complexes with $\mathrm{Ca}^{++}$if it is added in the solution (UV, color of the solutions).

The FTIR spectra of the metallic surfaces before and after grafting with GA are reported in Figures 3 and 4 .

Considering that the used functionalization procedure can develop on the metallic surfaces a thin (monomolecular) layer of GA [13], the FTIR signals, which are acquired within a penetration depth of at about $1 \mu \mathrm{m}$, are of moderate intensity because they are affected by the substrate presence.

On the polished Ti6AI4V surfaces, the signals accounted for the grafted molecules of GA are the small peaks respectively at about $2900 \mathrm{~cm}^{-1}$, attributable to the $\mathrm{C}-\mathrm{H}$ bonds, at $1735 \mathrm{~cm}^{-1}$, attributable to the $\mathrm{C}=\mathrm{O}$ bonds and at $1264 \mathrm{~cm}^{-1}$ attributable to the $\mathrm{C}-\mathrm{O}$ bonds $[17,28,29,30]$. These peaks are absent on the substrate before functionalization (Ti6Al4V-MP) as well as on the sample functionalized in water (Ti6Al4V-MP GA (wat)), while are detected on Ti6AI4V - MP GA (TRIS/HCl), Ti6Al4V - MP GA (TRIS/ $\mathrm{HCl}+\mathrm{CaCl}_{2}$ ). It can be 
concluded that the polished surface of this material has a low grafting ability, and the presence of the deprotonated carboxylic groups on $\mathrm{GA}$ and $\mathrm{Ca}^{2+}$ ions in the solution is mandatory for grafting.

On the chemically treated Ti6AI4V samples, the signals accounted for the grafted molecules of GA are the broad band between 3000 and $3600 \mathrm{~cm}^{-1}$ on Ti6AI4V - CT GA (water) and Ti6AI4V - CT GA (TRIS/HCl+CaCl 2 ) and can be attributed to the $\mathrm{OH}$ groups, as the signal at $1058 \mathrm{~cm}^{-1}$, while the peak at about $1600 \mathrm{~cm}^{-1} \mathrm{can}$ be associated with $\mathrm{C}-\mathrm{C}$ bonds $[17,28,29,30]$. All the signals attributable to the grafted $\mathrm{GA}$ are much more intense on Ti6AI4V-CT than the same signals on the MP substrate: this evidence a higher ability for grafting of the Ti6AI4V alloy after the surface treatment. This effect can be explained considering that Ti6Al4V-MP has very few surface functional groups, while Ti6Al4V-CT has a much higher density of OH groups [19]. No evidence of the presence of the grafted GA is detectable on Ti6AILV-CT (TRIS/HCl) which has a spectrum analogous to the substrate before functionalization (Ti6Al4V-CT). This effect can be explained by considering that the $\mathrm{OH}$ groups on Ti6Al4V-CT have a strong acid strength [32] and they are fully deprotonated at the physiological $\mathrm{pH}$ : the GA molecule deprotonated and negatively charged has no grafting ability on the negative charged surface of Ti6Al4V-CT (as observed on Ti6AI4V-CT (TRIS/HCI)), while GA has an electrostatic attraction for the surface in the protonated state (Ti6Al4V-CT (wat)) or like a complex with the $\mathrm{Ca}^{2+}$ ions (Ti6Al4V-CT (TRIS/ $\mathrm{HCl}+\mathrm{CaCl}_{2}$ ).

On the steel surfaces (Figure 4), a signal accounted for the grafted molecules of GA is the broad band between 3000 and $3600 \mathrm{~cm}^{-1}$ which can be slightly detected on SS $304 \mathrm{GA}$ (TRIS/HCl) and SS304 GA (TRIS $/ \mathrm{HCl}+\mathrm{CaCl}_{2}$ ) and attributed to the $\mathrm{OH}$ groups $[17,28,29,30]$. A broad band around $1600 \mathrm{~cm}^{-1} \mathrm{can}$ be observed on SS304 GA (TRIS/ $\mathrm{HCl}+\mathrm{CaCl}_{2}$ ) and SS $204 \mathrm{GA}$ (TRIS/ $\mathrm{HCl}+\mathrm{CaCl}_{2}$ ) and it is associated with the C-C bonds [17, 28, 29, 30]. Moreover, a signal at about $1060 \mathrm{~cm}^{-1}$, attributable to the $\mathrm{OH}$ groups [17, 28, 29, 30], can be detected on SS $304 \mathrm{GA}(\mathrm{TRIS} / \mathrm{HCl})$ and SS304 GA (TRIS/ $\mathrm{HCl}+\mathrm{CaCl}_{2}$ ) and on all the GA grafted SS 204-Cu surfaces. It can be concluded that also on the steels surfaces the $\mathrm{Ca}^{2+}$ ions are able to increase the grafting ability of GA giving much more evident FTIR signals.

A signal at about $1730 \mathrm{~cm}^{-1}$, as the one observed on Ti6AI4V - MP GA (TRIS/HCl) and Ti6AI4V - MP GA ( $T R I S / H C l+\mathrm{CaCl}_{2}$ ) and attributed to $\mathrm{C}=0$ bonds, is also visible on the steel surfaces; however in these cases it is also present on the bare material. This phenomenon can be associated with the interaction of steel surface with air, as reported in [33] or with an instrumental artifact and it is not significant for the evaluation of the grafting of GA. 


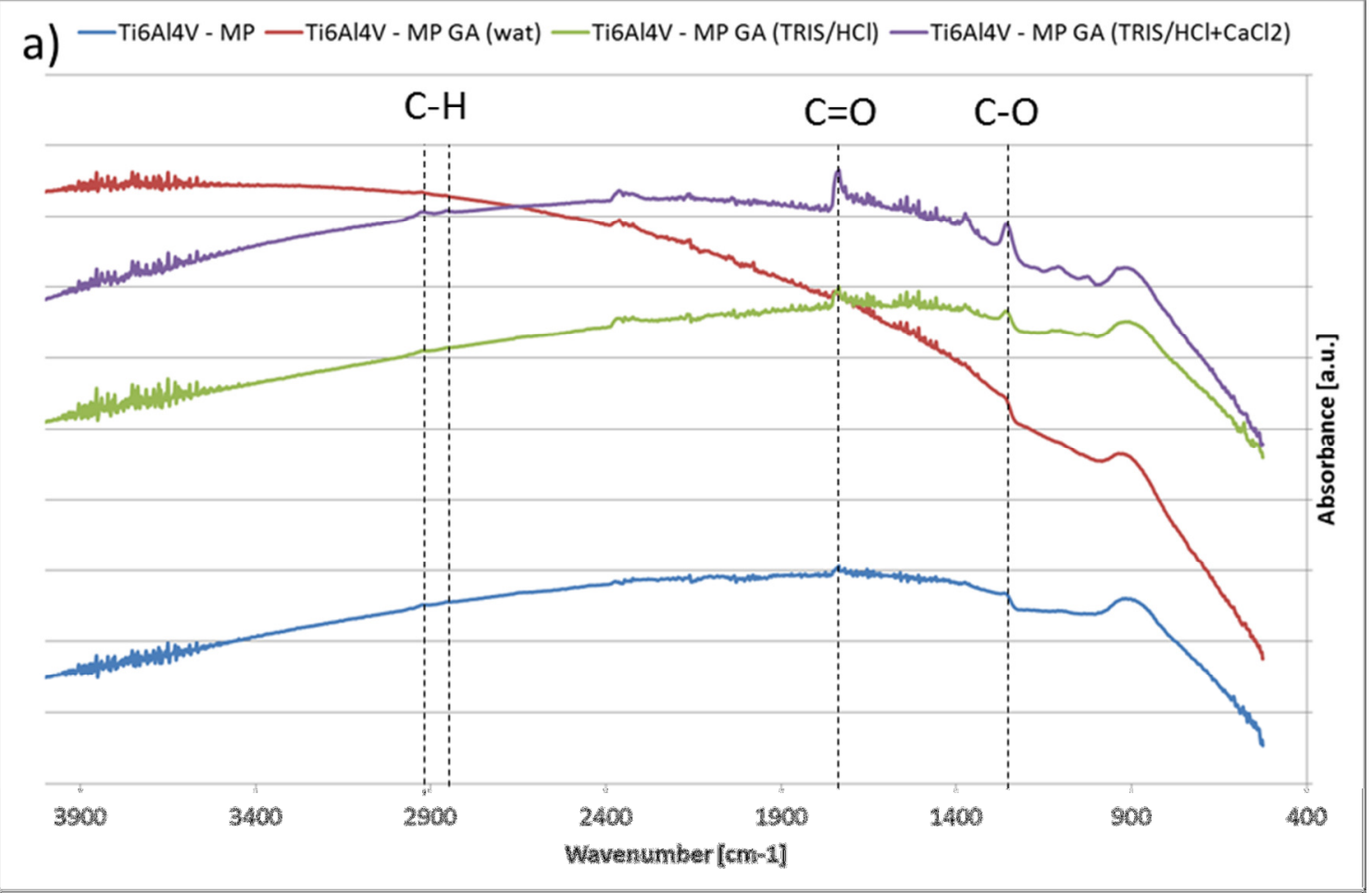

b) - Ti6Al4V - CT - Ti6Al4V - CT GA (water) - Ti6Al4V - CT GA (TRIS/HCl) - Ti6Al4V - CT GA (TRIS/HCl+CaCl2)

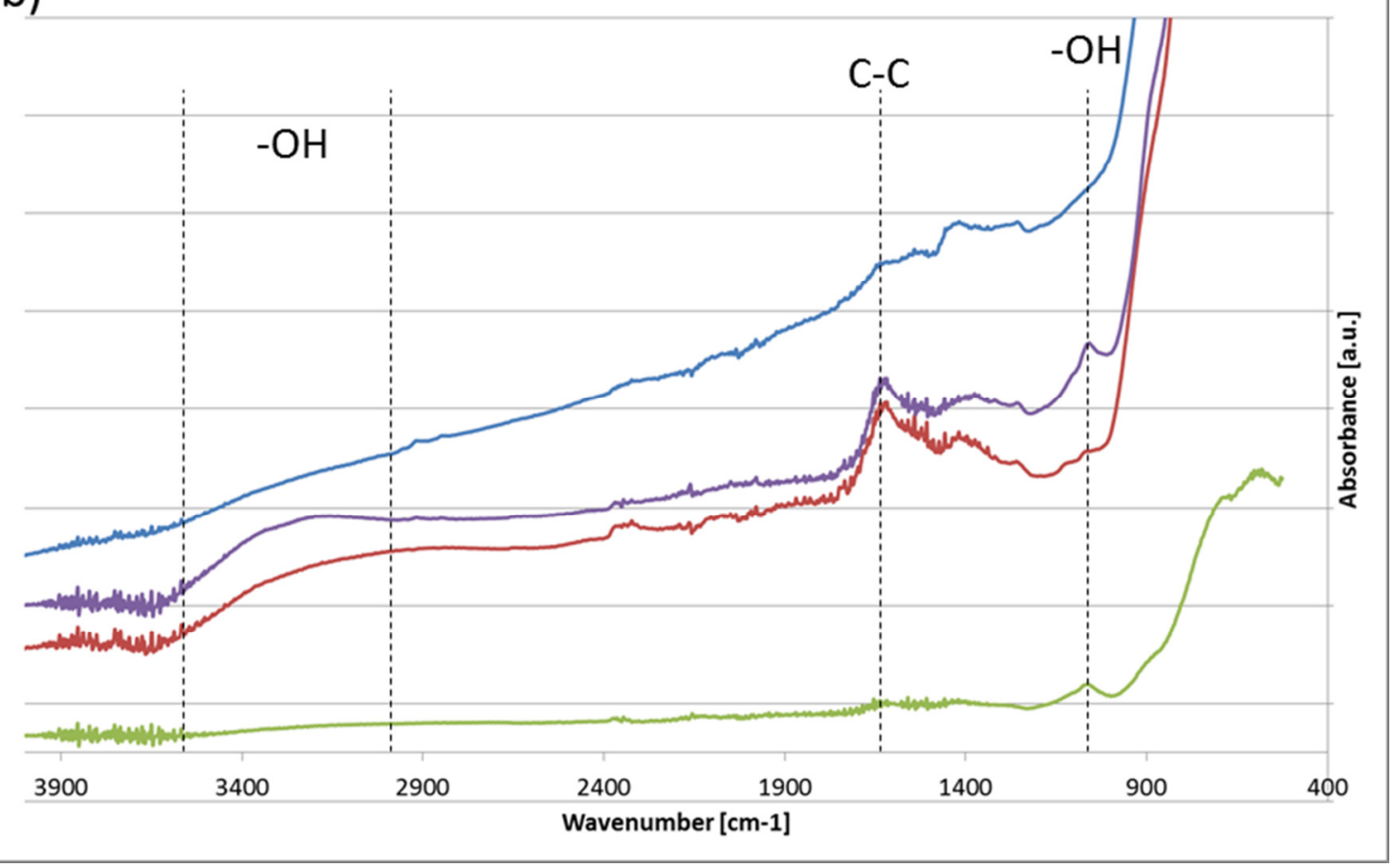

Figure 3: The FTIR spectra of the substrates and GA-grafted titanium surfaces: (a) polished Ti6AI4V, (b) chemically treated Ti6Al4V 


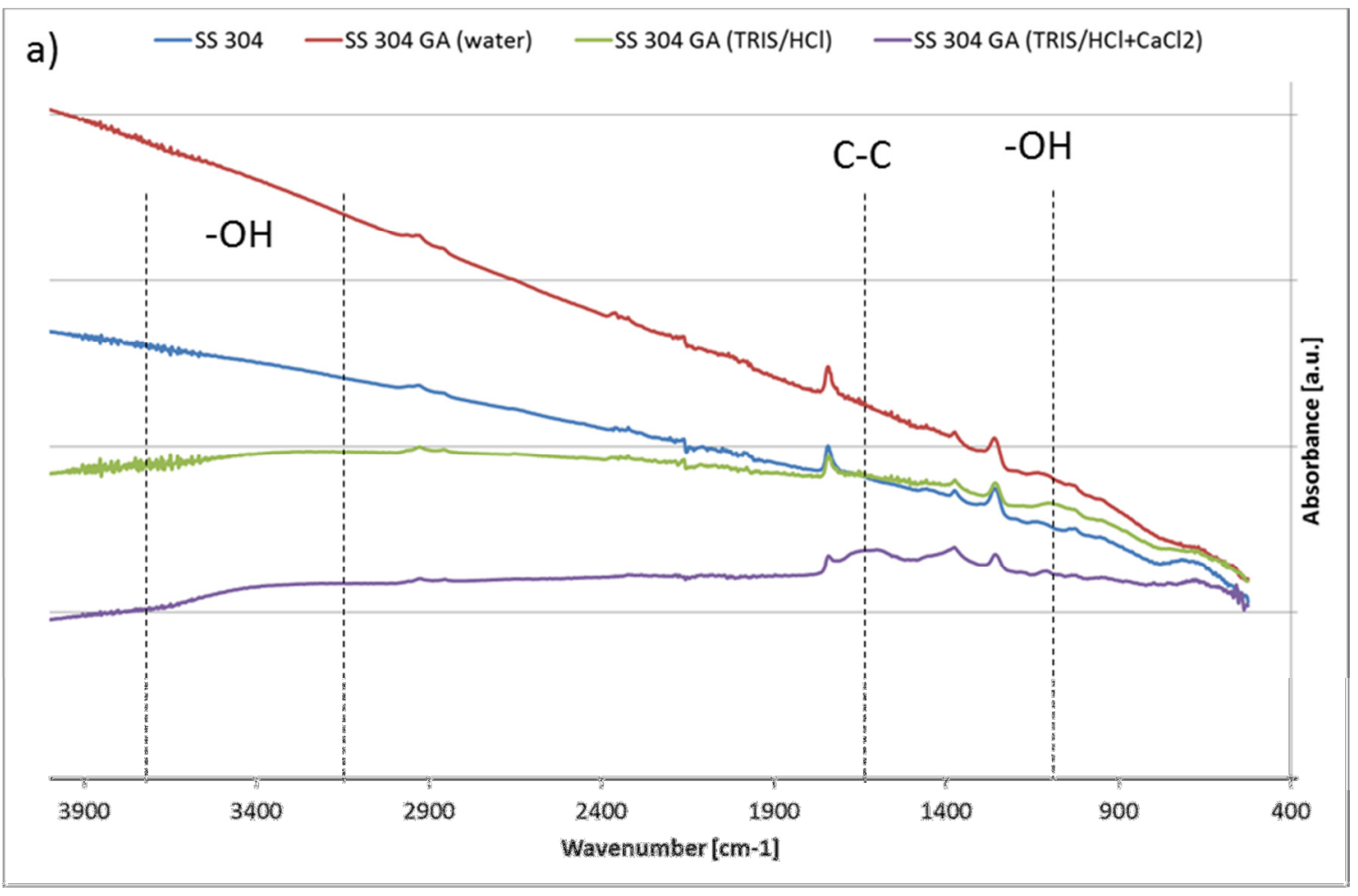

b) - $\mathrm{SS} 204 \mathrm{Cu}-\mathrm{SS} 204 \mathrm{Cu}$ GA (water) - $\mathrm{SS} 204 \mathrm{Cu} \mathrm{GA}(\mathrm{TRIS} / \mathrm{HCl})-\mathrm{SS} 204 \mathrm{Cu} \mathrm{GA}(\mathrm{TRIS} / \mathrm{HCl}+\mathrm{CaCl} 2)$

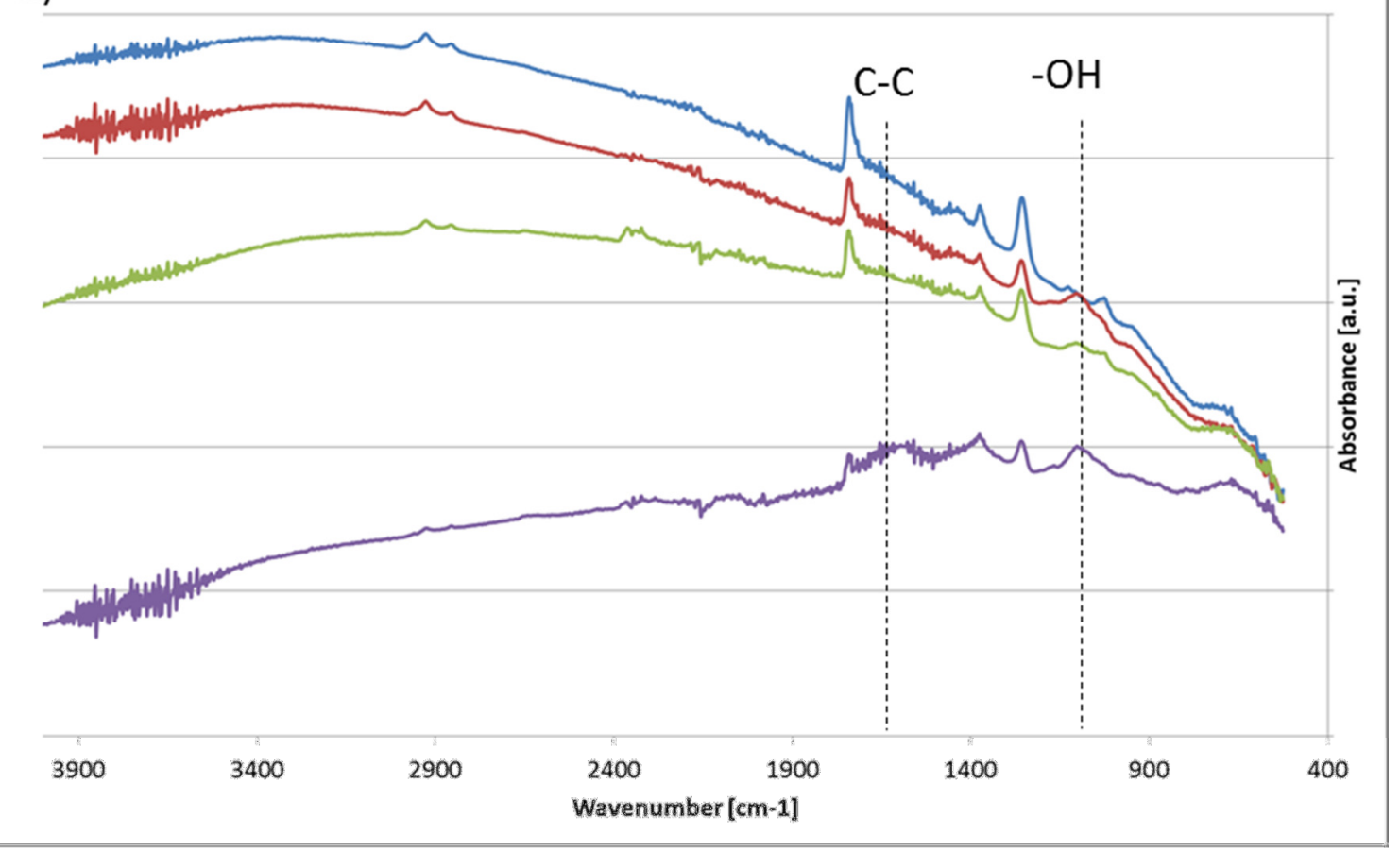

Figure 4: FTIR spectra of the substrates and GA-grafted steel surfaces :(a) SS 304, (b) SS 204-Cu The results of the Folin\&Ciocalteu test are reported in Figure 5. 


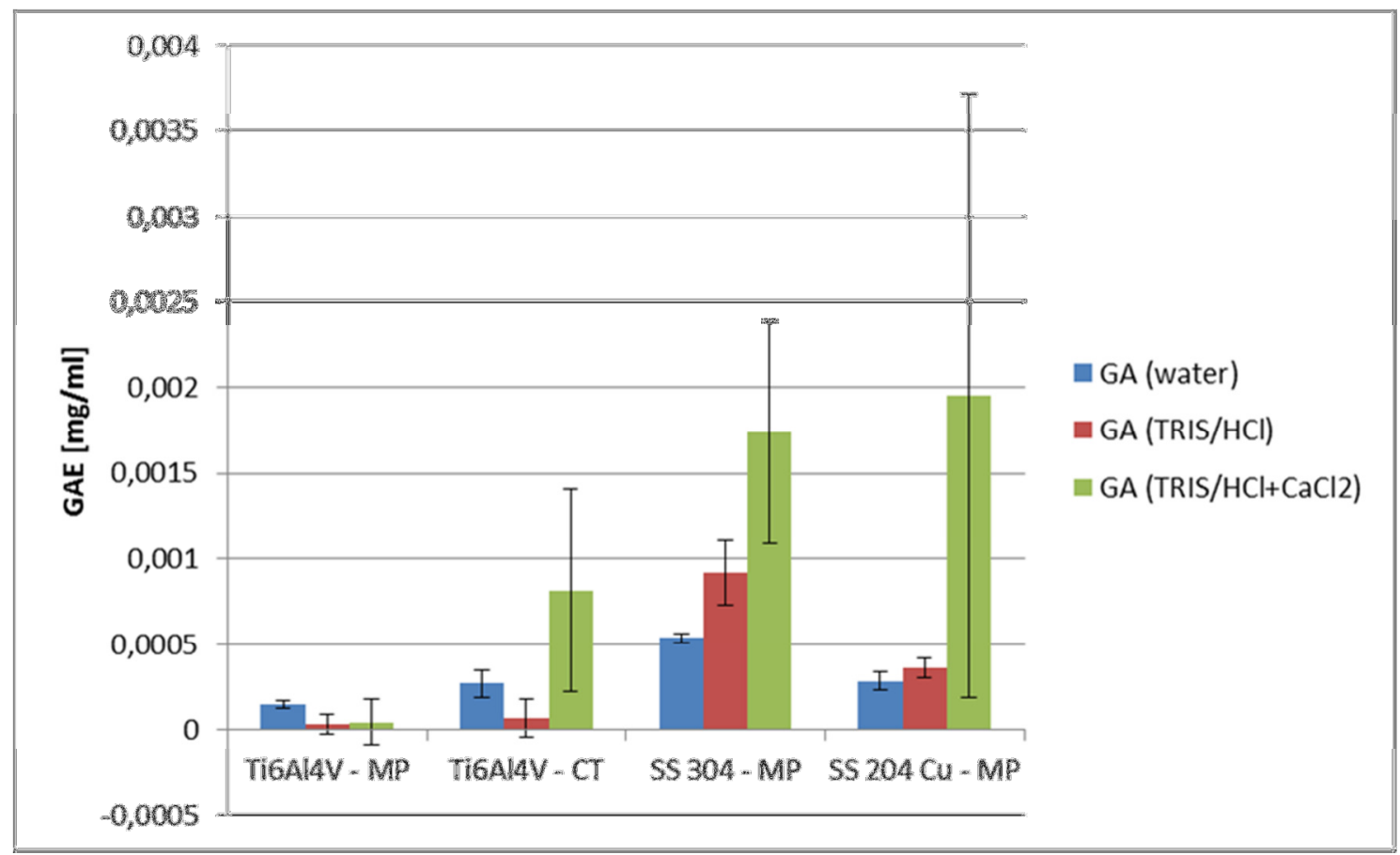

Figure 5: Redox activity of the GA grafted surfaces (Folin\&Ciocalteu test)

The amount of GA detected by the Folin \& Ciocalteu test results negligible on the surface polished Ti6AI4V samples while it increases on the chemically treated Ti6Al4V and particularly when the GA solution is prepared in a TRIS/HCl buffer added with $\mathrm{CaCl}_{2}$. This behavior is in agreement with the FTIR data and can be explained by considering that the Ti6AI4V - CT samples are rich in $\mathrm{OH}$ groups, which are suitable for GA grafting, and that the $\mathrm{Ca}^{++}$ions can mediate the bonding between the $\mathrm{Ti}-\mathrm{OH}$ groups and $\mathrm{GA}$ molecules through the formation of a heterogeneous ternary metal-ion complex, as previously reported by the authors [13]. All the here hypothesized Ca-gallic acid complexes are negatively charged and can interact with the negatively charged metallic surface through the formation of ternary complexes at the surface. A considerable amount of GA has been detected on the steel surfaces and it increases when grafting is performed in TRIS/HCl buffer or TRIS/HCl buffer added with $\mathrm{CaCl}_{2}$. A higher affinity of $\mathrm{GA}$ with the steel surfaces, compared to the titanium ones, can be explained by considering the high affinity of GA with the iron ions $[27,28]$. The role of calcium in this interaction, can be similar to the one described for titanium surfaces, but it should be investigated more in depth in the future.

The Folin \& Ciocalteu test is a further confirmation of the success of GA grafting on the metallic surfaces, moreover it underlines that GA maintains its redox activity after grafting. This point is of interest considering the exploitation of the GA properties on the metallic surfaces.

The results of the wettability tests are reported in Figure 6. 


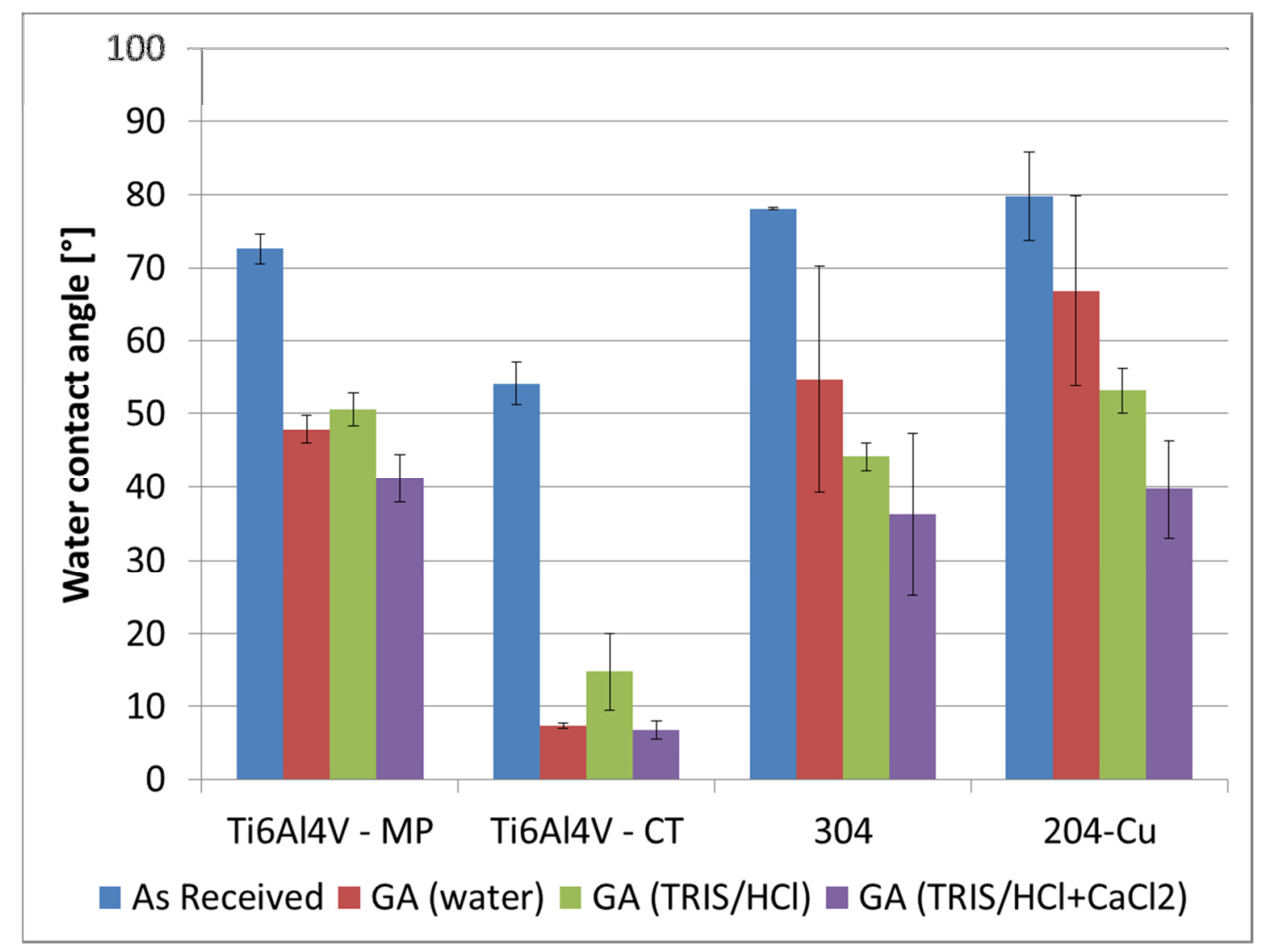

Figure 6: Wettability of bare and GA grafted metallic surfaces.

A reduction of the water contact angle (increase in wettability) can be observed on all surfaces after GA grafting. A decrease in the contact angle can be associated with the presence of the $\mathrm{OH}$ groups, characteristic of the GA molecule. This phenomenon is particularly evident for Ti6Al4V - CT, probably because this surface has a specific surface chemistry and exposes function groups $(\mathrm{OH})$ acting as a strong acid: this can result in a specific orientation of the grafted GA molecules with a higher exposition of their hydrophilic domain.

The wettability measurements appear a useful technique for the determination of the GA presence on metallic surfaces: it is simple, sensitive and able to evidence specific surface orientation of the grafted molecules. Moreover, wettability is a surface property of interest for several applications. In any case, the FTIR, UV and contact angle measurements must be used in a complementary way for a comprehensive understanding of the grafting process. The developed protocol allows a comprehension of the role on grafting of the surface chemistry of the substrate, the chemical state of the molecule in the solution, the presence of ions in the solution, the amount, surface distribution redox activity and orientation of the grafted molecule.

Summarizing the obtained results, gallic acid is in its fully protonated form in the acidic ultrapure water, its carboxylic group becomes deprotonated in neutral medium $(\mathrm{TRIS} / \mathrm{HCl})$ and possible partial oxidation occurs in these conditions (quinone formation). In neutral medium containing calcium ions (TRIS/ $\mathrm{HCl}+\mathrm{CaCl}_{2}$ ) the formation of several different negatively charged calcium-gallate complexes can be supposed, with higher stability with respect to oxidation. A partial polymerization of GA molecules in all solutions has also been evidenced (UV, FTIR).

When these solutions are put in contact with metallic surfaces different interactions can be supposed. 
In the acidic environment ( $\mathrm{pH}=3$ ) of $\mathrm{GA}$ (water) solution Ti6Al4V - MP and steels are negatively charged, because their isoelectric points are close to $4.5[32,34]$ while Ti6Al4V - CT is negatively charged (isoelectric point close to 2) [32]. In these conditions the electrostatic affinity between GA and Ti6AI4V - MP and steels is low while the one between GA and Ti6AI4V - CT is higher. This is fully confirmed by FTIR, F\&C and wettability data for titanium surfaces. A certain grafting of GA on steels surfaces occurred also in water and it can be correlated with the high affinity of GA for iron $[27,28]$.

In the neutral environment $(\mathrm{pH}=7.4)$ of $\mathrm{GA}(\mathrm{TRIS} / \mathrm{HCl})$ solution all surfaces are negatively charged and consequently do not have electrostatic affinity for deprotonated GA. In particular Ti6AI4V - CT presents a high amount of $\mathrm{OH}$ groups with a strong acid strength [32] and fully deprotonated at $\mathrm{pH}=7.4$. This behavior can explain the worst results of GA grafting on Ti6AI4V - CT in TRIS/HCl solution, compared to the other substrates. As discussed before certain grafting of GA on steels surfaces (even higher than in water) can be correlated with the high affinity of GA for iron $[27,28]$.

In the $\mathrm{GA}\left(\mathrm{TRIS} / \mathrm{HCL}+\mathrm{CaCl}_{2}\right)$ solution surfaces are still all negatively charged $(\mathrm{pH}=7.4)$ and $\mathrm{GA}$ is present in the form of negatively charged metal complexes (with various possible configurations). In this case an increased ability of grafting has been recorded (FTIR, F\&C, wettability) on all materials and can be explained considering the formation of ternary complexes at the metallic surfaces (as reported by the authors in [13] for Ti6Al4V - CT) with $\mathrm{Ca}^{2+}$ as intermediate cation. The possible role of iron in this environment should be further investigated.

Finally it can be observed that the polymerization of GA in the various solution, evidenced in the present work, can have a role in the grafting ability, in fact, it has been reported that this phenomenon can reduce the solubility of polyphenol in solution and increase their ability to form coatings on material surfaces [35]. This point is of particular interest for the optimization of grafting condition and will be further investigated.

\section{Conclusions}

GA solutions have been prepared in different media (water, TRIS/HCl buffer and TRIS/HCl buffer added with $\mathrm{CaCl}_{2}$ ) and characterized by means of UV and FTIR spectroscopies, in order to explore the role of $\mathrm{pH}$ and the ionic composition on the GA grafting ability. GA has a different chemical state and polymerization degree in the different solutions. GA has been successfully grafted on different metallic surfaces: Ti6Al4V polished and chemically treated, SS 304 and SS 204-Cu polished. Its presence has been verified by means of FTIR spectroscopy, Folin\&Ciocalteu and wettability tests. A crucial role of the medium used for the preparation of the GA functionalization solution has been highlighted, evidencing an important action of the $\mathrm{Ca}^{2+}$ ions in the binding mechanisms. A crucial role on the grafting ability and on the orientation of the grafted molecules is also played by the surface chemistry of the substrate and the presence of functional groups on it. The grafted GA molecules effectively maintain their redox ability on the different metallic

surfaces. Moreover, a protocol for the characterization of the modified surfaces has been developed for the first time. This work is the preliminary step for a future research on the surface modification of metals with natural molecules, which can be a green approach for the obtainment of smart functional surfaces for several applications. 


\section{References}

[1] Z.B. Lu, G.J. Nie, P.S. Belton, H.R. Tang, B.L. Zhao, Structure-activity relationship analysis of antioxidant ability and neuroprotective effect of gallic acid derivatives, Neurochem. Int. 48 (2006) 263-274.

[2] S. Quideau, D. Deffieux, C. Douat-Casassus, L. Pouysegu, Plant Polyphenols: Chemical properties, Biological activities and synthesis, Angew. Chem. Int Ed. 50 (2011) 586-621.

[3] L Bravo, Polyphenols: Chemistry, dietary sources, metabolism and nutritional significance, Nutr. Rev. 56 (1998) 317-333.

[4] Z.B. Lu, G.J. Nie, P.S. Belton, H.R. Tang, B.L. Zhao, Structure-activity repationship analysis of antioxidant ability and neuroprotective effect of gallic acid derivatives, Neurochem. Int. 48 (2006) 263-274.

[5] D.S. Ming, B.J. Hillhouse, E.S. Guns, A. Eberding, S.W. Xie, S. Vimalanathan, G.H.N. Towers, Bioactive compounds from Rhodiola rosea (Crassulaceae), Phytother Res.19 (2005) 740-743.

[6] V.L. Singleton, J.A. Rossi, Colorimetry of total phenolics with phosphomolybdic -phosphotungstic acid reagents, Am. J. Enol. Vitic. 16 (1965) 144-158.

[7] W Pasanphan, G R. Buettner, S Chirachanchai, Chitosan gallate as a novel potential polysaccharide antioxidant: an EPR study, Carbohydrate Research 345 (2010) 132-140

[8] S. A. Moreno-A' Ivarez, G. A. Martı́nez-Castanon, N. Nin o-Martı́nez, J. F. Reyes-Macı' as, N. PatinoMarın, J. P. Loyola-Rodrı'guez, Facundo Ruiz, Preparation and bactericide activity of gallic acid stabilized gold nanoparticles, J Nanopart Res (2010) 12:2741-2746

[9] K Raina, S Rajamanickam, G Deep, M Singh, R Agarwal, C Agarwal, Chemopreventive effects of oral gallic acid feeding on tumor growth and progression in TRAMP mice, Mol Cancer Ther2008;7(5). May 2008

[10] X Zhang, S Ferraris, E Prenesti, E Verné, Surface functionalization of bioactive glasses with natural molecules of biological significance, Part I: Gallic acid as model molecule, Applied Surface Science 287 (2013) 329- 340

[11] S Ferraris, X Zhang, E Prenesti, I Corazzari, F Turci, M Tomatis, E Vernè, Gallic acid grafting to a ferrimagnetic bioactive glass-ceramic, Journal of Non-Crystalline Solids 432 (2016) 167-175

[12] I Corazzari, Maura Tomatis, F Turci, S Ferraris, E Bertone, E Prenesti, E Vernè, Gallic acid grafting modulates the oxidative potential of ferrimagneticbioactive glass-ceramic SC-45, Colloids and Surfaces B: Biointerfaces 148 (2016) 592-599

[13] M Cazzola, S Ferraris, E Prenesti, V Casalegno, S Spriano, Grafting of Gallic Acid onto a Bioactive Ti6Al4V Alloy: A Physico-Chemical Characterization, Coatings 2019, 9, 302; doi:10.3390/coatings9050302

[14] M. Zheng, C. Zhang, Y. Zhou, Z. Lu, H. Zhao, X. Bie, F. Lu, Preparation of gallic acid grafted chitosan using recombinant bacteria laccase and its application in chilled meat preservation, Front Microbiol 9 (2018) 1729

[15] A M. L. Sousa, T-D Li, S Varghese, P J. Halling, K H A Lau, Highly Active Protein Surfaces Enabled by Plant-Based Polyphenol Coatings, ACS Appl. Mater. Interfaces 2018, 10, 39353-39362 
[16] B. Rajib, M. Larif, G. Mouhssine, A. Elmidaoui, M. E. Touhami, A. Chaouch, Valorization of polyphenols extracted from olive mill wastewater as ecological corrosion inhibitor on carbon steel in acid medium, Der Pahrma Chemica 8 (2016) 145-153

[17] A. Krilov., A. Holmgren, R. Gref, LO Ohman, Effects of gallic acid on metals: an FT-IR study of complexes between gallic acid and sawblade steel, Holzforshung 47 (1993) 239-246

[18] A.M. Fraser, M.A. Pascall, Cleaning and Sanitization of Food-contact Surfacesin Retail/Foodservice Establishments, http://www.foodsafetymagazine.com/ (accessed 9 october 2019, 12:41)

[19] M. Ferraris, S. Perero, S. Ferraris, M. Miola, E. Vernè, S. Skoglund, E. Blomberg, I. Odnevall Wallinder, Antibacterial silver nanocluster/silica composite coatings on stainless steel, Applied Surface Science 396 (2017) 1546-1555

[19] S. Ferraris, S. Spriano, G. Pan, A. Venturello, C.L Bianchi, R. Chiesa, M.G. Faga, G. Maina, E Vernè., Surface modification of Ti-6Al-4V alloy for biomineralization and specific biological response: Part I, inorganic modification, J Mat Sci Mat Med, 22 (2011) 533-545

[20] Spriano, S.; Vernè, E.; Ferraris, S. Multifunctional Titanium Surfaces for Bone Integration. EP Patent 2 214732,11 August 2010

[21] Ferraris S.; Spriano S.; Bianchi C.L.; Cassinelli C.; Vernè E. Surface modification of Ti-6Al-4V alloy for biomineralization and specific biological response: Part II, Alkaline phosphatase grafting, Journal of Materials Science: Materials in Medicine, 22 (2011): 1835-1842. DOI: 10.1007/s10856-011-4365-9

[23] Cazzola, Martina; Corazzari, Ingrid; Prenesti, Enrico; Bertone, Elisa; Vernè, Enrica; Ferraris, Sara Bioactive glass coupling with natural polyphenols: Surface modification, bioactivity and anti-oxidant ability, Applied Surface Science, 367 (2016): 237-248. DOI: 10.1016/j.apsusc.2016.01.138

[24] L. Lu, Y. Li, X. Lu, Kinetic study of the complexation of gallic acid with Fe(II), Spectrochimica Acta Part A 74 (2009) 829-834

[25] AC.Mera, D.Contreras, N.Escalona, HD.Mansilla, BiOl microspheres for photocatalytic degradation of gallic acid, Journal of Photochemistry and Photobiology A: Chemistry 318 (2016) 71-76

[26] E. Giannakopoulos, E. Isari, K. Bourikas, H.K. Karapanagioti, G. Psarras, G. Oron, I.K. Kalavrouziotis, Oxidation of municipal wastewater by free radicals mechanism. A UV/Vis spectroscopy study, Journal of Environmental Management 195 (2017) 186e194

[27] NR Perron, JL Brumaghim, A review of the antioxidant mechanism of polyphenols compounds related to iron binding, Cell Biochem Biophys 53 (2009) 75-100

[28] X. Mu, C. Yan, Q. Tian, J. Lin, S. Yang, BSA-assisted synthesis of ultrasmall gallic acid-Fe(III) coordination polymer nanoparticles for cancer theranostics, International Journal of Nanomedicine 2017:12 7207-7223

[29] S Naz, A R Khaskheli, A Aljabour, H Kara, F N Talpur, S T H Sherazi, A A Khaskheli, S Jawaid Synthesis of Highly Stable Cobalt Nanomaterial Using Gallic Acid and Its Application in Catalysis, Advances in Chemistry 2014, 686925, 6 pages

[30] M. Martı, V. Martınez, N Carreras, C Alonso, M J Lis, JLParra, L Coderch, Textiles with gallic acid microspheres: in vitro release characteristics, J Microencapsul. 2014;31(6):535-4 
[31] E. Giannakopoulos, E. Isari, K. Bourikas, H.K. Karapanagioti, G. Psarras, G. Oron, I.K. Kalavrouziotis, Oxidation of municipal wastewater by free radicals mechanism. A UV/Vis spectroscopy study, Journal of Environmental Management 195 (2017) 186e194

[32] S Ferraris, M Cazzola, V Peretti, B Stella, S Spriano, Zeta Potential Measurements on Solid Surfaces for in Vitro Biomaterials Testing: Surface Charge, Reactivity Upon Contact With Fluids and Protein Absorption. Front. Bioeng. Biotechnol. 6 (2018) 60.

[33] M A Frank, C Meltzer, B Braunschweig, W Peukert, A R. Boccaccini, S Virtane,Functionalization of steel surfaces with organic acids: Influence on wetting and corrosion behavior, Applied Surface Science 404 (2017) 326-333

[34] Spriano, S., Sarath Chandra, V., Cochis, A., Uberti, F., Rimondini, L., Bertone, E., Vitale, A., Scolaro, C., Ferrari, M., Cirisano, F., Gautier di Confiengo, G., Ferraris, S., How do wettability, zeta potential and hydroxylation degree affect the biological response of biomaterials? , Materials Science and Engineering $\mathrm{C}$ 74 (2017) 542-555

[35] TS Sileika, DG Barrett, R Zhang, KHA Lau, PB Messersmith, Colorless multifunctional coatings inspired by polyphenols found in tea, chocolate and wine, Angew. Chem. Int. 52 (2013) 10766-10770 